\title{
Detection of Neospora caninum (Toxoplasmatidae) in wild small mammals from Thailand
}

\author{
Ornampai Japa ${ }^{1}$, Serge Morand ${ }^{2}$, Anamika Karnchanabanthoeng ${ }^{3}$, Kittipong Chaisiri ${ }^{4}$ and Alexis Ribas $^{5,6}$ \\ ${ }^{1}$ Division of Microbiology and Parasitology, School of Medical Sciences, University of Phayao, Thailand; \\ ${ }^{2}$ CNRS ISEM-CIRAD ASTRE, Faculty of Veterinary Technology, Kasetsart University, Bangkok, Thailand; \\ 3 Vettech, Faculty of Veterinary Technology, Kasetsart University, Bangkok, Thailand; \\ ${ }^{4}$ Department of Helminthology, Faculty of Tropical Medicine, Mahidol University, Bangkok, Thailand; \\ ${ }^{5}$ Section of Parasitology, Department of Biology, Healthcare and the Environment, Faculty of Pharmacy and Food Sciences, \\ University of Barcelona, Barcelona, Spain; \\ ${ }^{6}$ Institute of Vertebrate Biology of the Czech Academy of Sciences, Brno, Czech Republic
}

\begin{abstract}
The presence of Neospora caninum Dubey, Carpenter, Speer, Topper et Uggla, 1988 in small mammals (i.e. murid rodents, Erinaceomorpha, Eulipotyphla and Scadentia) was explored for first time in South-East Asia. A total of 192 individuals from six localities across Thailand were analysed. A general prevalence of $N$. caninum of $22 \%$ was observed, with some variation among localities (5-36\%). Four main types of habitat were included and rodents trapped in dry-land habitat (17 positive among 41 individuals) were more likely to be infected with $N$. caninum than those from other habitats (forest, rain-fed land and settlement). Rodent species identity and individual rodent weight had no influence on individual infection. Our results provided the first data on the presence of $N$. caninum in rodents in South-East Asia and first report of N. caninum in the order Scadentia.
\end{abstract}

Keywords: DNA, Apicomplexa, rodent, South-East Asia

Neosporosis is a major cause of reproductive losses in cattle and the associated economic cost, e.g. loss of calf and reduction of milk yield. It is one of the most common congenitally transmitted diseases (Dubey et al. 2017) and there is no doubt of the veterinary importance of this disease. The definitive hosts of Neospora caninum Dubey, Carpenter, Speer, Topper et Uggla, 1988 are restricted to canids (dogs, coyote and gray wolf according to Dubey et al. 2017). In Thailand, Arunvipas et al. (2012) reported from serological investigations that dogs living on dairy farms in the western provinces of Thailand were exposed to $N$. caninum in relation to high prevalence of infection in the cattle herd. However, there is a lack of data on wild mammals in Asia that can act as intermediate hosts by acquiring from soil oocysts expelled in faeces from canids. The detection of DNA of cysts of $N$. caninum in the tissues of intermediate hosts would help to fill this gap.

Wild and commensal rodents (order Rodentia) are ubiquitous and can reach high densities in favourable environmental conditions, which make them potential intermediate hosts. However, there is a complete lack of information on the occurrence of $N$. caninum in Asian rodents. According to the review by Dubey et al. (2017) of all available literature, the DNA of $N$. caninum was found in rodent tissues in Europe and in a few instances from the American continent. In Europe, $N$. caninum has been reported from the common vole Microtus arvalis (Pallas) in Austria (infected 4 of 268 animals examined) and the Netherlands (1 of 24), the field mouse Apodemus sylvaticus (Linnaeus) in Italy ( 2 of 55) and the Netherlands (3 of 17), the harvest mouse Micromys minutus (Pallas) in The Netherlands (1 of 6), and the voles of the genus Arvicola Linnaeus in Austria (2 of 86). In America, this coccidian was reported in capybaras Hydrochaeris hydrochaeris (Linnaeus) in Brazil (3 of 26) and in squirrels Otospermophilus variegatus (Erxleben) in Mexico (3 of 6).

There were also positive surveys for DNA of $N$. caninum in two commensal rodents distributed worldwide: the house mouse (Mus musculus Linnaeus) in Europe, Australia and America, and in the Norway rat Rattus norvegicus (Berkenhout) in Europe, Mexico, Grenada and Taiwan. The unique study of this coccidian parasite in Asia, i.e. Taiwan by Huang et al. (2004), reported a positive seroprevalence of $N$. caninum in $16 \%$ and $4 \%$ by detection of DNA tissues in commensal $R$. norvegicus $(\mathrm{n}=55)$ from cattle farms. The study of Huang et al. (2004) highlights the importance of investigating wild rodents, although it remains difficult to assess the role played by Norway rats in the transmis-

Address for correspondence: A. Ribas, Section of Parasitology, Department of Biology, 33 Healthcare and the Environment, Faculty of Pharmacy and Food Sciences, University of Barcelona, Barcelona, Spain. E-mail: aribas@ub.edu 
sion of $N$. caninum. Regarding mammals of the order Eulipotyphla (i.e. shrews), surveys showed DNA positive for N. caninum for the soricids Crocidura russula (Hermann) and Sorex araneus Linnaeus in the Netherlands. As the Asian house shrew Suncus murinus (Linnaeus) is found in or near human habitation and other synanthropic habitats in South-East Asia (Corbett and Hill 1992), the investigation of potential infection of the Asian house shrew by $N$. caninum is of interest.

In Thailand, neosporosis in dairy cattle is a major concern, among many other diseases, by lowering production of milk and meat. Inpankaew et al. (2014) recorded a prevalence of $47 \%$ by ELISA and of $34 \%$ by IFAT in 642 cattle studied. The water buffalo with an estimated population of 1.2 million in Thailand is of big importance for agriculture, and $N$. caninum has also been reported in this bovid with an overall seroprevalence of 9\% (Kengradomkij et al. 2015). The objective of the present study was to investigate the potential role of small mammals, mainly rodents, as intermediate hosts of $N$. caninum in South-East Asia and to assess if host habitat, body weight and species affect the level of individual infection.

\section{Small mammal sampling}

Rodent species included in the study are neither on the CITES list nor the Red List (IUCN). Animals were treated in accordance with the guidelines of the American Society of Mammalogists, and within the European Union legislation guidelines (Directive 86/609/EEC). Each trapping campaign was validated by the national and local health authorities. Approval notices for trapping and investigation of rodents were provided by the Ethical Committee of Mahidol University, Bangkok, Thailand (number 0517.1116/661).

To assess a representative sampling, field surveys took place from 2011 to 2016 . Small mammals were collected by live-trapping from six sites and a total of 192 animals were investigated. Across Thailand, the six sites were: two sites in Nan Province: Bo Kleu District (1908'37"N; 101 $09^{\prime} 04^{\prime \prime E}$, year 2014) and Tha Wang Pha District $\left(19^{\circ} 08^{\prime} 23^{\prime \prime N}\right.$; $100^{\circ} 43^{\prime} 11^{\prime \prime E}$, year 2015); one site in Chantaburi Province (12³0'32"N; 10207'36"E, year 2015); Chiang Rai Province (1953'28"N; 099³4'15"E, year 2016); Kanchanaburi Province (14 $11^{\circ} 11^{\prime \prime N}$; 099 07'40"E, year 2011) and Songkla Province $\left(07^{\circ} 16^{\prime} 60^{\prime \prime N}\right.$; $100^{\circ} 30^{\prime} 00^{\prime \prime} \mathrm{E}$, year 2013$)$.

Within each locality, an area of approximately $10 \mathrm{~km}^{2}$ was designated for rodent trapping covering four habitat types (forest, dry land, rain-fed land - paddy fields, and human settlement) that were sampled at each locality. For each of the first three categories 10 trap-lines (10 traps by line separated $10 \mathrm{~m}$ each trap) were set over a four-night period during each trapping session. This corresponded to a total of 1,200 night-traps per trapping session for each locality. Locally made live cage traps were used and the lines were placed in the same positions during each trapping session using GPS coordinates. Villages and isolated houses, which corresponded to the fourth habitat category, human settlement, were also sampled opportunistically us- ing cage-traps distributed to residents. No intensive cattle farms were included in our study.

Rodent species were identified in the field using morphological criteria, but were confirmed using molecular methods if needed using a mitochondrial gene for barcoding of some rodent species (Galan et al. 2012). Complete data on the animals used as reference specimens for the barcoding assignment are available on the "Barcoding Tool/RodentSEA" section of the CERoPath project web site (www.ceropath.org).

Small mammals were euthanised using isoflurane as inhalant anaesthetic agent in a closed chamber on the day of trapping at the local field stations. Morphological characteristics and morphometry were assigned for species identification in distinct specimens following Marshall et al. (1998) and Aplin et al. (2003), whereas molecular applications (both nuclear and mitochondrial markers) were used in problematic samples as published by Pagès et al. (2010). A piece of liver was preserved in absolute ethanol in the fridge for further analysis.

\section{PCR screening of DNA of Neospora caninum}

A $100 \mathrm{mg}$ sample of small mammal liver was subjected to DNA extraction using Tissue Genomic DNA Mini Kit (Geneaid) according to the manufacturer's instructions, The extracted DNA was stored at $-20^{\circ} \mathrm{C}$ until used. The PCR targeting the NC-5 gene was carried out following Muller et al. (1996) using NC6+ (5'- CTCGCCAGTCAACCTACGTCTTCT-3') and NC21+ (5'- CCCAGTGCGTCCAATCCTGTAAC-3'). The expected size of $N$. caninum PCR product fragment was about $340 \mathrm{bp}$. In brief, $2 \mu \mathrm{l}$ of DNA template from each sample was subjected to a $25 \mu \mathrm{l}$ PCR reaction containing $0.2 \mu \mathrm{M}$ of each primer, $200 \mu \mathrm{M}$ of each dNTP, $1.5 \mathrm{mM}$ of $\mathrm{MgCl} 2$ and $2.5 \mathrm{U}$ of Taq DNA polymerase in Coral Load PCR buffer, pH 8.7 (Qiagen, Hilden, Germany).

For each set of PCR amplification, $N$. caninum (Nc-1 or Nc-2) reference isolates were included as an internal positive control. Negative control, including reaction without DNA template and DNA of Toxoplasma gondii (Nicolle et Manceaux, 1908) were included in each PCR amplification. The PCR program with the thermal cycler was pre-denaturing at $94^{\circ} \mathrm{C}$ for $5 \mathrm{~min}$; 40 cycles of $94^{\circ} \mathrm{C}$ for $30 \mathrm{~s}, 63^{\circ} \mathrm{C}$ for $30 \mathrm{~s}$ and $72^{\circ} \mathrm{C}$ for $1 \mathrm{~min}$ and a final extension cycle at $72^{\circ} \mathrm{C}$ for $5 \mathrm{~min}$. The amplified PCR products were visualised on $1.5 \%$ Agarose gel pre-stained with Nancy-520 (Sigma-Aldrich, Dorset, UK) under UV light and gel images were recorded by Gel document.

\section{Statistical analysis}

The probability of infection with $N$. caninum was modelled as a function of several factors with a logistic regression (GLMM with logit function) using package lme4 (Bates et al. 2015) implemented in $\mathrm{R}$ freeware ( $\mathrm{R}$ Core Team 2017). Cases in each logistic regression were infected or non-infected individual rodents.

The initial model included the explanatory variables relating to each individual rodent, species identification and weight, and the main habitats where they were trapped 
(forest, dry agricultural land, rain-fed land and settlement). No interactions were added among the independent variables. Locality was included as a random variable.

Support for competing models was evaluated investigating the relationship between the occurrence of $N$. caninum and all explanatory variables of interest. Likelihood-based methods (Burnham et al. 2002) was used to quantify the alternative models and to estimate their parameters. AIC adjusted for sample size (AICc) was used to assess the relative information content of the models. The uncertainty that the 'best' model would emerge as superior if different data were used with Akaike weights $\mathrm{w}_{\mathrm{f}}$ was quantified (Burnham et al. 2002). Selection of the best competing models was made using package gmulti version 1.0.7 (Calcagno and de Mazancourt 2010) implemented in R, which allows the exploration of all models using automated model selection and model-averaging procedure.

\section{Collected small mammals}

In total, 192 small mammals were trapped, belonging mainly to Rodentia (95\%) including the genera Bandicota Gray, Berylmys Ellerman, Maxomys Sody, Menetes Thomas, Mus Linnaeus, Niviventer Marshall and Rattus Fischer. Specimens of Erinaceomorpha (Hylomys suillus Müller; $\mathrm{n}=4)$; Eulipotyphla (S. murinus; $\mathrm{n}=1)$ and Scandentia (the common treeshrew, Tupaia glis [Diard et Duvaucel]; $\mathrm{n}=5$ ) were also trapped.

\section{Molecular results}

The mean prevalence of infection with $N$. caninum was $22 \%$, varying between localities as follows: Bo Kleu $5 \%$; Chantaburi 18\%; Chiang Rai 23\%; Kanchanaburi 36\%; Songkla $28 \%$ and Tha Wang Pha $24 \%$.

\section{Statistical modelling}

The statistical modelling was performed on 192 individuals with 43 positive for infection with $N$. caninum. The first top model among all potential candidate models that fitted the entire dataset with variables related to rodent species, individual weight and trapping habitat using logit function showed that the only explanatory variable was trapping habitat $\left(\mathrm{AICc}=205.7, \mathrm{w}_{\mathrm{f}}=0.28\right)$. Hence, the first best top model selected using AICc values demonstrated that rodents trapped in dry-land habitat (17 positive among 41 individuals) were more likely to be infected with $N$. caninum (odds ratio $=2.35$ ) than those trapped in other habitats (6/34 in forest, 2/22 in rain-fed land, 17/52 in settlement). Rodent species and individual weight had no influence on individual infection.

Our results provide the first data of the presence of $N$. caninum in rodents in South-East Asia and the first data from Asia except a study from Taiwan (Huang et al. 2004) in commensal rats. Few studies on N. caninum in rodents have been conducted worldwide, as emphasised by the recent review by Dubey et al. (2017). Despite the limited number of individuals of $T$. glis studied, we were able to provide the first report of detection of DNA of $N$. caninum in the Scadentia. The lack of or under sampling of several mammalian groups could explain the limited
Table 1. Comparison of the three top models explaining the infection of individual rodents by Neospora caninum using GLMM with logit function. Models are ranked from lowest to highest supported according to corrected Akaike information criteria (AIC). The initial model included the following explanatory variables: species identification, weight and the main habitats where they were trapped (forest, dry agricultural land, rain-fed land and settlement). No interactions were added among the independent variables. We included locality as a random variable. See that AIC weights decreased sharply from the first model $\left(\mathrm{w}_{\mathrm{f}}=28 \%\right)$ to the second best model $\left(\mathrm{w}_{\mathrm{f}}=11 \%\right)$ and to the third best model $\left(\mathrm{w}_{\mathrm{f}}=1 \%\right)$.

\begin{tabular}{lllc} 
Models (best top 3) & K & AICc & $\mathrm{w}_{\mathrm{f}}$ \\
\hline Habitat & 2 & 205.7 & 0.28 \\
Rodent individual weight & 2 & 207.6 & 0.11 \\
Habitat + rodent individual weight & 6 & 207.8 & 0.01 \\
\hline \multicolumn{4}{l}{ K - number of estimated parameters; } \\
tion criteria; $\mathrm{w}_{\mathrm{f}}-$ the Akaike weights
\end{tabular}

knowledge of some orders and families. The only sample of the shrew S. murinus was negative. Future screenings will be required to confirm a potential association of this shrew with $N$. caninum. The presence of this coccidian in all surveyed sites indicates that rodents could be involved in maintaining the life cycle of the protozoan in agricultural areas with the presence of water buffaloes and/or with free roaming cattle.

In addition, our results show that the environments studied were contaminated by oocysts of $N$. caninum, with potential infection risks for cattle. Some habitats seem to play a role as a factor for infection of small mammals. This observation calls for complementary studies considering habitat as a risk factor for $N$. caninum. Comparison of prevalence with previous studies in wild rodents is difficult as most surveys are based on screening of brain tissues.

The study of Medina-Esparza et al. (2013) showed a detectability variation depending on target organs (brain, spinal cord, liver and heart), with liver as the best organ to detect $N$. caninum cysts. However, the studies by Machačová et al. (2016) based on wild small mammals (n $=427$ ) caught in the Czech Republic were unable to detect this parasite in liver samples. Combination of organs from each individual host will increase detectability in rodents as emphasised by Medina-Esparza et al. (2013).

Despite these technical issues, our results show that rodents could act as intermediate hosts of $N$. caninum and may play a significant role in the epidemiology of $N$. caninum. However, a better assessment of transmission within habitats should be considered. In conclusion, our results describe the considerably high prevalence of $N$. caninum in rodents in South-East Asia and provide the first report of $N$. caninum in the Scadentia. These hosts maintain the transmission of the parasite in agricultural environments. Rodents appeared as bioindicators or sentinels of the presence of $N$. caninum in a range of habitats where domestic species such as livestock were not present.

Acknowledgements. This study was funded by the French ANR CP\&ES, grant ANR 11 CPEL 002 BiodivHealthSEA project (www.biodivhealthsea.org). 


\section{REFERENCES}

Aplin K.P., Brown P.R., Jacob J., Krebs C.J., Singleton G.R. (EDS.) 2003: Field methods for rodent studies in Asia and the Indo-Pacific. ACIAR Monograph No. 100, Canberra, 223 pp.

Arunvipas P., InPankaew T., Jittapalapong S. 2012: Risk factors of Neospora caninum infection in dogs and cats in dairy farms in Western Thailand. Trop. Anim. Hlth. Prod. 44: 11171121.

Bates D., MäChler M., Bolker B., Walker S. 2015: Fitting linear mixed-effects models using lme4. J. Stat. Softw. 67: 1-48.

Burnham K.P., Anderson D.R. (Eds.) 2002: Model Selection and Multimodel Inference: A Practical Information - Theoretic Approach. Springer-Verlag, New York, 488 pp.

Calcagno V., de Mazancourt C. 2010: Glmulti: an R package for easy automated model selection with (generalised) linear models. J. Stat. Softw. 34: 1-29.

Corbett G.B., Hill J.E. (Eds.) 1992: The Mammals of the Indomalay Region: A Systematic Review. Natural History Museum Publications, Oxford University Press, Oxford, 488 pp.

Dubey J.P., Hemphill A., Schares G., Calero-Bernal R. (EDS.) 2017: Neosporosis in Animals. CRC Press, Boca Raton, $530 \mathrm{pp}$.

Galan M., Pagès M., Cosson J.F. 2012: Next-generation sequencing for rodent barcoding: species identification from fresh, degraded and environmental samples. PLoS ONE. 7: e48374.

Huang C.C., Yang C.H., Watanabe Y., Liao Y.K., Ooi H.K. 2004: Finding of Neospora caninum in the wild brown rat (Rattus norvegicus). Vet. Res. 35: 283-290.

InPankaew T., Jittapalapong S., Mitchell T., Sununta C., IgARASHi I., XUAN X. 2014: Seroprevalence of Neospora caninum infection in dairy cows in northern provinces, Thailand. Acta Parasitol. 59: 305-309.
Kengradomkij C., Inpankaew T., Kamyingkird K., Wongpanit K., Wongnakphet S., Mitchell T.J, Xuan X., IGarashi I., Jittapalapong S., Stich R.W. 2015: Seroprevalence and risk factors associated with exposure of water buffalo (Bubalus bubalis) to Neospora caninum in northeast Thailand. Vet. Parasitol. 207: 156-160.

Machačová T., Ajzenberg D., Žákovská A., Sedlák K., BárToví E. 2016: Toxoplasma gondii and Neospora caninum in wild small mammals: seroprevalence, DNA detection and genotyping. Vet. Parasitol. 223: 88-90.

Marshall J. 1998: Rats and mice. In: B. Lekagul and J.A. McNeely (Eds.), Mammals of Thailand. Association for the Conservation of Wildlife, Bangkok, pp. 397-487.

Medina-Esparza L., Macías L., Ramos-Parra M., MoRales-Salinas E., Quezada T., Cruz-Vázquez C. 2013: Frequency of infection by Neospora caninum in wild rodents associated with dairy farms in Aguascalientes, Mexico. Vet. Parasitol. 191: 11-14.

Müller N., Zimmermann V., Hentrich B., Gottstein B. 1996: Diagnosis of Neospora caninum and Toxoplasma gondii infection by PCR and DNA hybridization immunoassay. J. Clin. Microbiol. 34: 2850-2852.

Pagès M., Chaval Y., Herbreteau V., Waengsothorn S., Cosson J.F., Hugot J.P., Morand S., Michaux J. 2010: Revisiting the taxonomy of the Rattini tribe: a phylogeny-based delimitation of species boundaries. BMC Evol. Biol. 10: 184.

R Core Team 2017: R: A Language and Environment for Statistical Computing, www.r-project.org.

Cite this article as: Japa O., Morand S., Karnchanabanthoeng A., Chaisiri K., Ribas A. 2018: Detection of Neospora caninum (Toxoplasmatidae) in wild small mammals from Thailand. Folia Parasitol. 65: 018. 